\title{
Nonenzymatic Glucose Sensor Based on In Situ Reduction of Ni/NiO-Graphene Nanocomposite
}

\author{
Xiaohui Zhang ${ }^{1,2,+}$, Zheng Zhang ${ }^{1, *,+}$, Qingliang Liao ${ }^{1}$, Shuo Liu ${ }^{1}$, Zhuo Kang ${ }^{1}$ and \\ Yue Zhang ${ }^{1,3, *}$ \\ 1 State Key Laboratory for Advanced Metals and Materials, School of Materials Science and Engineering, \\ University of Science and Technology Beijing, Beijing 100083, China; Zhangxiaohui@crrcgc.cc (X.Z.); \\ liao@ustb.edu.cn (Q.L.); ruodehaner123@126.com (S.L.); zhuokang@ustb.edu.cn (Z.K.) \\ 2 CRRC Institute, Beijing 100070, China \\ 3 Beijing Municipal Key Laboratory for Advanced Energy Materials and Technologies, Beijing 100083, China \\ * Correspondence: zhangzheng@ustb.edu.cn (Z.Z.); yuezhang@ustb.edu.cn (Y.Z.); Tel.: +86-10-6233-4725 (Y.Z.) \\ $\dagger$ These authors contributed equally to this work. \\ Academic Editor: Huangxian Ju \\ Received: 22 August 2016; Accepted: 17 October 2016; Published: 26 October 2016
}

\begin{abstract}
Ni} / \mathrm{NiO}$ nanoflower modified reduced graphene oxide (rGO) nanocomposite (Ni/NiO-rGO) was introduced to screen printed electrode (SPE) for the construction of a nonenzymatic electrochemical glucose biosensor. The Ni/NiO-rGO nanocomposite was synthesized by an in situ reduction process. Graphene oxide (GO) hybrid Nafion sheets first chemical adsorbed Ni ions and assembled on the SPE. Subsequently, GO and Ni ions were reduced by hydrazine hydrate. The electrochemical properties of such a Ni/NiO-rGO modified SPE were carefully investigated. It showed a high activity for electrocatalytic oxidation of glucose in alkaline medium. The proposed nonenzymatic sensor can be utilized for quantification of glucose with a wide linear range from $29.9 \mu \mathrm{M}$ to $6.44 \mathrm{mM}(\mathrm{R}=0.9937)$ with a low detection limit of $1.8 \mu \mathrm{M}(\mathrm{S} / \mathrm{N}=3)$ and a high sensitivity of $1997 \mu \mathrm{A} / \mathrm{mM} \cdot \mathrm{cm}^{-2}$. It also exhibited good reproducibility as well as high selectivity.
\end{abstract}

Keywords: nonenzymatic; glucose; graphene; biosensor; in situ

\section{Introduction}

Diabetes is a worldwide public health problem and one of the leading causes of death and disability [1]. The diagnosis and management of diabetes mellitus requires serious monitoring of blood glucose levels. Since Clark and Lyons first proposed the concept of glucose enzyme electrodes in 1962 [2], glucose sensors have become the most important biosensors, not only in research field but also in the market for the past 50 years [3]. Electrochemical sensors based on glucose dehydrogenase and glucose oxidase have been extensively studied due to their high selectivity and good sensitivity towards glucose [4,5]. The inevitable disadvantages of enzymes still limit the measurement and analytical application of enzyme electrodes based glucose sensors, such as the chemical or thermal instabilities originated from the intrinsic nature [6-8].

Nonenzymatic electrocatalysis to direct oxidation of glucose is a feasible alternative technology that is free from the mentioned drawbacks. It depends on the current response of glucose oxidation directly at the electrode surface to achieve high sensitivity and the selectivity. Generally, the key electrode materials of nonenzymatic sensors consist of the nanostructures of transition metals and their alloys, such as copper [9], platinum [10], palladium [11], nickel [12], etc. Compared with these metals structures, $\mathrm{Ni}$ and its chemical compound, such as Ni nanowire array [13], NiO hollow microsphere [14], and $\mathrm{Ni}(\mathrm{OH})_{2}$ nanoplates [15], are proven to allow production of high sensitivity glucose sensors at low cost [16,17]. Further, the oxidation processes of glucose, which is catalyzed 
by nickel, are through the formation of a high-valent, oxyhydroxide species $(\mathrm{NiOOH})$ in alkaline medium [13].

Graphene, a one atom thick material consisting of sp2 bonded carbon with a honeycomb structure, has drawn a vast amount attention since its discovery [18] ascribing to its excellent physical and chemical properties [19]. Graphene's high surface area, easy functionalization, excellent electron transfer, and good biocompatibility, make it become a super platform for biological analysis and detection [20-22]. The application of graphene in developments of nonenzymatic sensors would provide high reliability and stability for glucose analysis and monitoring. Thus, recently, researchers started to focus on Ni-graphene hybrid for enzyme free glucose detection [23,24]. CuNiO nanocubic modified graphene sheets showed wide linear range up to $16 \mathrm{mM}$ [25]; $\mathrm{Ni}(\mathrm{OH})_{2}$ nanoplates on reduced graphene oxide (rGO) exhibited low detection limit of $0.6 \mu \mathrm{A}$.

With the motivation of developing a miniaturized lab-on-chip device for routine glucose measurement, we employed replaceable and disposable screen printed electrodes (SPEs) to construct enzyme-free glucose sensors, modified by Ni/NiO-rGO nanocomposite. The synthesis of the nanocomposite is initiated by electrostatic process and formation of self-assembled nanocomposite precursors of negatively charged graphene oxide $(\mathrm{GO})$ and positively nickel cations $\left(\mathrm{Ni}^{2+}\right)$. The resulting nanocomposite facilitated electron transfers and endowed high electrocatalytic activity for non-enzymatic glucose sensing. It provided high sensitivity, rapidity, simplicity and reproducibility advantages.

\section{Experimental Methods}

\subsection{Regents and Apparatus}

Graphene oxide (GO) dispersion was commercial obtained from Nanjing XFNANO Materials Tech Co., Ltd. (Nanjing, China); Glucose and nickel acetate $\left(\mathrm{Ni}\left(\mathrm{CH}_{3} \mathrm{COOH}\right)_{2}\right)$ were purchased from Sinopharm Chemical Reagent Co., Ltd. (Shanghai, China); 5\% Nafion ethanol solution, lactic acid (LA), uric acid (UA), bull serum albumin (BSA), and ascorbic acid were obtained from Sigma-Aldrich; and Screen printed electrodes (SPEs, AC1.W4.RS) were constructed by BVT Technologies.

The morphologies and structures of rGO sheets were characterized by employing FESEM (Zeiss, SUPRA-55), Raman spectrometer (Jobin-Yvon, JY-HR800, 514 nm), and XPS (Axis UltraDLD). The cyclic voltammetric and amperometric response measurements of Ni/NiO-Nafion-rGO/SPEs were investigated by advanced electrochemical interface (Solartron Analytical, SI 1287).

\subsection{Rinse and Activation of SPES}

Before reducing process, SPEs were rinsed under ultrasonic agitation for $3 \mathrm{~min}$ by the mixture of sulfuric acid (volume fraction $5 \%$ ), hydrochloric acid (volume fraction $5 \%$ ), potassium hydroxide $(0.5 \mathrm{~mol} / \mathrm{L})$, and phosphate buffer solution (PBS, $0.1 \mathrm{~mol} / \mathrm{L}, \mathrm{pH}=7.4)$. To accelerate the electron transfer and enhance the electrochemical activity of SPEs, electrochemical activation [26] was conducted under $1.5 \mathrm{~V}$ for $180 \mathrm{~s}$.

\subsection{In Situ Synthesis of Ni/NiO-rGO Modified SPEs}

The mixture of Nafion solution $(5 \mathrm{wt} . \%, 100 \mu \mathrm{L})$ and GO dispersion $(0.5 \mathrm{~g} / \mathrm{L}, 100 \mu \mathrm{L})$ was incubated for $30 \mathrm{~min}$ at room temperature to format GO-Nafion hybrid. Nafion was utilized to the in situ synthesis of $\mathrm{Ni} / \mathrm{NiO}-\mathrm{rGO}$ nanocomposite for introducing the negative charges for the electrostatic and self-assembled precursors. Then, nickel acetate solution $\left(\mathrm{Ni}\left(\mathrm{CH}_{3} \mathrm{COOH}\right)_{2}, 0.1 \mathrm{~mol} / \mathrm{L}\right.$, $60 \mu \mathrm{L})$ is added to GO-Nafion hybrid $(20 \mu \mathrm{L})$ and incubated for $60 \mathrm{~min}$. During such incubation, $\mathrm{Ni}^{2+}$ would chemically absorb on GO sheets. Then, the work electrode of SPE was immersed in the proposed Nafion-GO-Ni ${ }^{2+}$ mixture for $30 \mathrm{~min}$ to immobilize $\mathrm{GO}$ and $\mathrm{Ni}^{2+}$. Finally, hydrazine hydrate $\left(\mathrm{N}_{2} \mathrm{H}_{4} \cdot \mathrm{H}_{2} \mathrm{O}, 10 \mathrm{mmol} / \mathrm{L}\right)$ was exerted on the work electrode of SPEs for $20 \mathrm{~h}$ at room temperature to 
in situ reduce $\mathrm{GO}$ and $\mathrm{Ni}^{2+}$. The formation mechanism of in situ synthesized $\mathrm{Ni} / \mathrm{NiO}-\mathrm{rGO}-\mathrm{Nafion}$ nanocomposite is shown in Scheme 1.

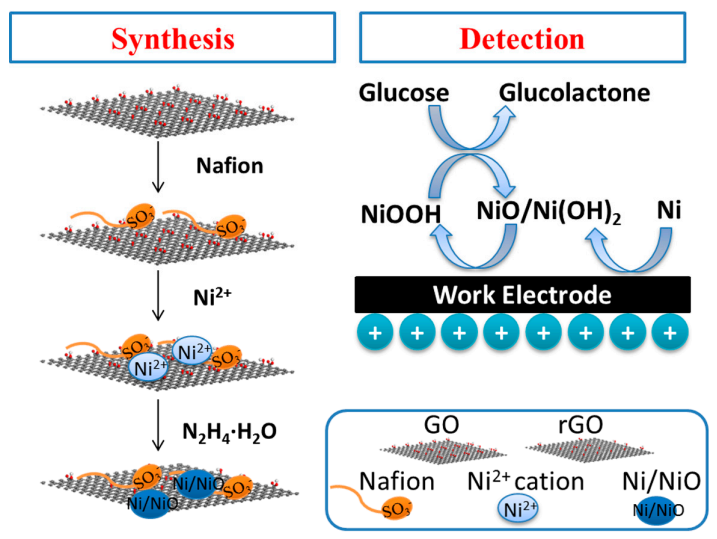

Scheme 1. The in situ synthesis of the Ni/NiO-rGO nanocomposite and the detection principle of the electrocatalysis of glucose.

\section{Results and Discussion}

\subsection{Morphology and Structure Characterization}

FESEM morphologies of GO and in situ reduced Ni/NiO-rGO nanocomposite are shown in Figure 1a,b. Both GO and rGO sheets are in micrometer size and obviously wrinkled structures. Flower-like $\mathrm{Ni} / \mathrm{NiO}$ nanoparticles with the size of 300-400 nm (insert Figure 1b) are dispersed on rGO sheet homogeneously. Elemental composition of Ni/NiO-rGO nanocomposite was determined by surface EDS (Figure 1c). Signature peaks of $\mathrm{C}, \mathrm{O}$, and Ni were characterized, and a weak peak indicating $\mathrm{N}$ from the reduce agent hydrazine hydrate is also obtained.
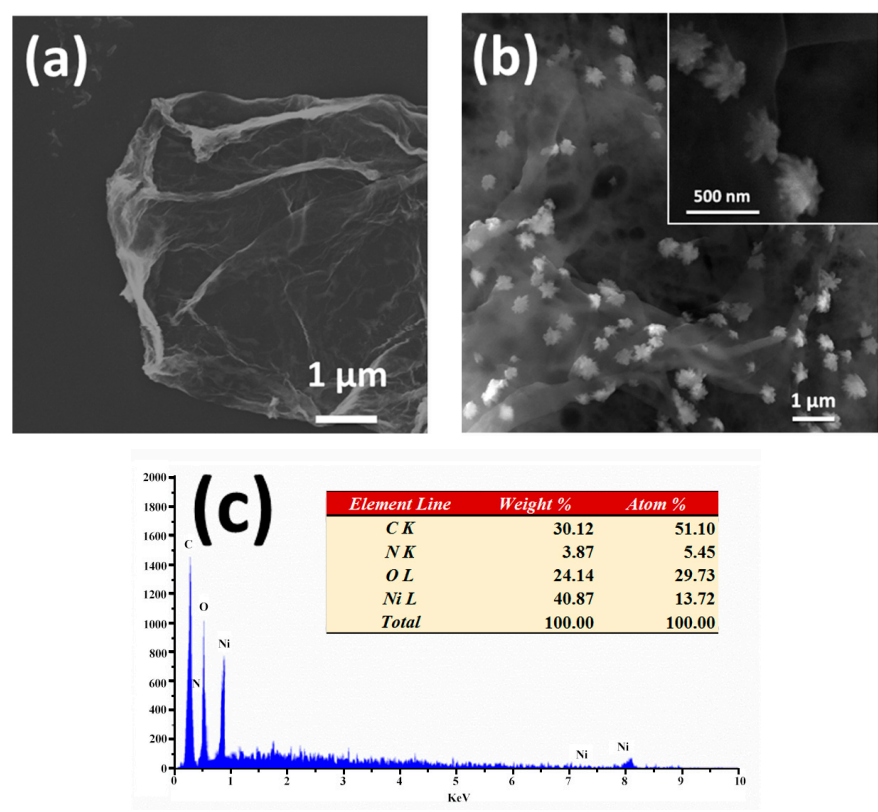

Figure 1. (a) FESEM morphologies of GO; and (b) Ni/NiO-rGO; and (c) surface EDS spectrum of $\mathrm{Ni} / \mathrm{NiO}-\mathrm{rGO}$.

The structural characterization of $\mathrm{GO}$ and $\mathrm{Ni} / \mathrm{NiO}-\mathrm{rGO}$ sheets was further performed by analyzing the Raman spectra, as shown in Figure 2a. The well-defined D bands $\left(\sim 1350 \mathrm{~cm}^{-1}\right)$, 
characteristic of the first-order scattering from a zone-boundary phonon [27], are strong in both GO and $\mathrm{Ni} / \mathrm{NiO}-\mathrm{rGO}$ samples, which indicates the defective crystal structures for both $\mathrm{GO}$ and Ni/NiO-rGO. Besides, $2 \mathrm{~cm}^{-1}$ negative shift observed after modified progress, suggesting the successful reduction of GO [28]. G band $\left(\sim 1600 \mathrm{~cm}^{-1}\right)$ is assignable to the E2g phonon of sp2 carbon atoms. The intensity ratio of $\mathrm{D}$ to $\mathrm{G}$ band $\left(\mathrm{I}_{\mathrm{D}} / \mathrm{I}_{\mathrm{G}}\right)$ reflects the defect density of graphene sheets. $\mathrm{I}_{\mathrm{D}} / \mathrm{I}_{\mathrm{G}}$ increased from 0.97 to 1.10 after reduction, demonstrating the defects formation during reduction and $\mathrm{Ni} / \mathrm{NiO}$ assembling. $2 \mathrm{D}$ bands $\left(\sim 2670 \mathrm{~cm}^{-1}\right)$, representative of the second-order zone-boundary phonons, are relatively week in both $\mathrm{GO}$ and $\mathrm{Ni} / \mathrm{NiO}-\mathrm{rGO}$, indicating the multilayers structures of grapheme [29].
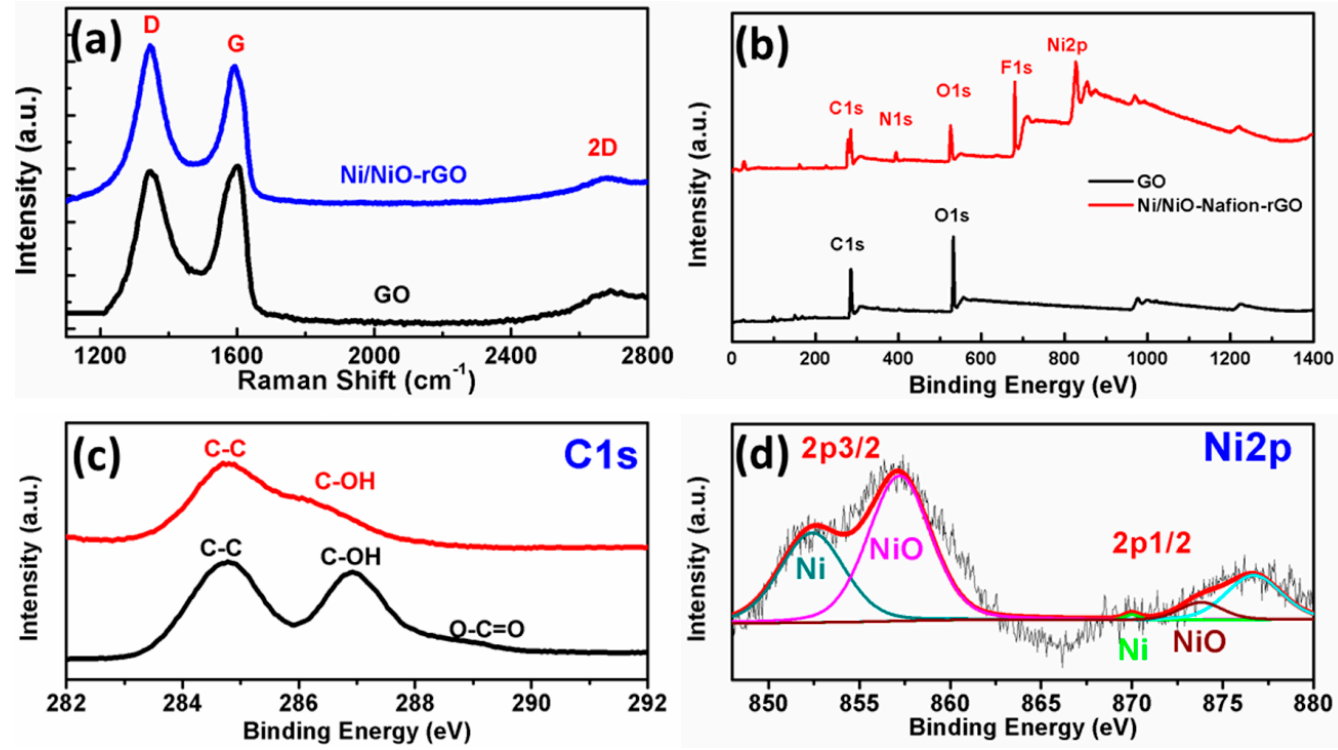

Figure 2. Structure characterization of the in-situ reduction of Ni/NiO-rGO nanocomposite: (a) Raman spectra of GO (black curve) and Ni/NiO-rGO nanocomposite (blue curve); (b) Entire XPS spectra of GO (black curve) and Ni/NiO-Nafion-rGO nanocomposite (red curve); (c) XPS spectra of C1s for GO and $\mathrm{Ni} / \mathrm{NiO}-\mathrm{Nafion}-\mathrm{rGO}$; and (d) XPS spectrum of Ni2p for Ni/NiO-Nafion-rGO.

The functional groups and the Ni content in graphene sheets were conducted by XPS spectra (Figure $2 b-d$ ). As shown in the entire XPS spectra (Figure 2b), peaks of C1s and O1s are relevantly strong in both GO and Ni/NiO-Nafion-rGO. Compared to GO, additional peaks of N1s, F1s and $\mathrm{Ni} 2 \mathrm{p}$ resulting from hydrazine hydrate residual, Nafion and $\mathrm{Ni}$ element in $\mathrm{Ni} / \mathrm{NiO}-\mathrm{Nafion}-\mathrm{rGO}$ are observed. The atomic content of $\mathrm{C}$ and $\mathrm{O}$ in $\mathrm{GO}$ sheets is calculated to be $69.8 \%$ and $39.2 \%$, respectively. Accordingly, the atomic content of $\mathrm{C}, \mathrm{N}, \mathrm{O}, \mathrm{F}$ and $\mathrm{Ni}$ in $\mathrm{Ni} / \mathrm{NiO}-\mathrm{Nafion}-\mathrm{rGO}$ are determined to be $52.8 \%, 3.4 \%, 10.4 \%, 7.2 \%$ and $26.2 \%$, respectively. This reveals that the atomic ratio of $\mathrm{C}$ and $\mathrm{O}(\mathrm{C}: \mathrm{O})$ increased from 1.76 to 5.08 after reduction, which is also supported by Raman spectra results. Moreover, the oxygen related functional group, $\mathrm{C}-\mathrm{OH}$ and $\mathrm{O}-\mathrm{C}=\mathrm{O}$, are obviously reduced in $\mathrm{Ni} / \mathrm{NiO}-\mathrm{Nafion}-\mathrm{rGO}$ compared to GO (Figure 2c). The great number of surface oxygen functional groups on GO sheets can play the role of cation adsorption and nucleation sites for metal nanoparticles [30]. Accordingly, the effective deoxygenating of GO by the in situ reduction process improved the electrical conductivity of graphene that can be the supportive material in catalyst layers [9].

$\mathrm{Ni} 2 \mathrm{p}$ spectrum of $\mathrm{Ni} / \mathrm{NiO}-\mathrm{Nafion}-\mathrm{rGO}$ is shown in Figure $2 \mathrm{~d}$. The main satellite peaks at 857.2 and $876.7 \mathrm{eV}$ are generally caused by multi-electron excitation [31]. According to these "shake-up" peaks, four separated peaks, located at 852.4, 857.2, 870.0 and $873.8 \mathrm{eV}$, represent metallic $\mathrm{Ni}(2 \mathrm{p} 3 / 2), \mathrm{NiO}(2 \mathrm{p} 3 / 2)$, metallic $\mathrm{Ni}(2 \mathrm{p} 1 / 2)$ and $\mathrm{NiO}(2 \mathrm{p} 1 / 2)$, respectively [32,33]. The as-synthesized $\mathrm{Ni} / \mathrm{NiO}-\mathrm{Nafion}-\mathrm{rGO}$ nanocomposite would greatly affect the electrochemical properties of modified SPEs in alkaline medium. 


\subsection{Electrochemical Characterizations}

Cyclic voltammograms (CVs) are performed on bare SPE, Ni/NiO-SPE, rGO/SPE, and $\mathrm{Ni} / \mathrm{NiO}-\mathrm{Nafion}-\mathrm{rGO}-\mathrm{SPE}$, as shown in Figure 3a. In the presence of $0.1 \mathrm{M} \mathrm{NaOH}$, the current of rGO-SPE is considerably enhanced compared to the bare SPE. Moreover, no redox peak is observed towards both bare SPE and rGO-SPE, suggesting no oxidation-reduction reaction occurred in alkaline medium without nickel catalyzing. A pair of asymmetric redox peak at $0.450 \mathrm{~V}$ and $0.402 \mathrm{~V}$ is observed for Ni/NiO-SPE (insert of Figure 3a). As Ni/NiO-rGO incorporates onto the SPEs, the current is significantly increased comparing to $\mathrm{Ni} / \mathrm{NiO}-\mathrm{SPE}$, and a pair of well-defined asymmetric redox peak at $0.444 \mathrm{~V}$ and $0.387 \mathrm{~V}$ is observed, which could be attributed to the electron transfer between $\mathrm{Ni}$ (II) and $\mathrm{Ni}$ (III) [14]:

$$
\mathrm{NiO}+\mathrm{OH}^{-} \rightarrow \mathrm{NiOOH}+\mathrm{e}^{-}
$$

Furthermore, the metallic Ni on rGO sheets would experience the reaction of $\mathrm{Ni}(0)$ to $\mathrm{Ni}$ (II), and then $\mathrm{Ni}$ (II) to $\mathrm{Ni}$ (III) [34]:

$$
\begin{gathered}
\mathrm{Ni}+2 \mathrm{OH}^{-} \rightarrow \mathrm{Ni}(\mathrm{OH})_{2}+2 \mathrm{e}^{-} \\
\mathrm{Ni}(\mathrm{OH})_{2}+\mathrm{OH}^{-} \rightarrow \mathrm{NiOOH}+\mathrm{H}_{2} \mathrm{O}+\mathrm{e}^{-}
\end{gathered}
$$
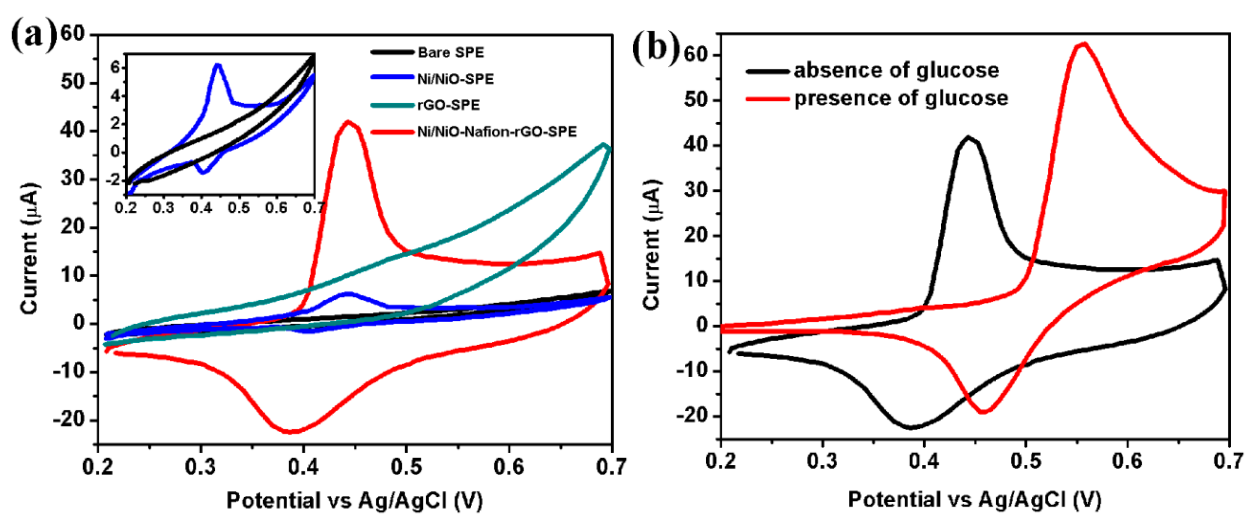

Figure 3. (a) Cyclic voltammograms of bare SPE, rGO-SPE, Ni/NiO-SPE and Ni/NiO-rGO-SPE in $0.1 \mathrm{M} \mathrm{NaOH}$ at scan rate of $50 \mathrm{mV} / \mathrm{s}$ (insert show the magnification of bare SPE and Ni/NiO-SPE); (b) Cyclic voltammograms of Ni/NiO-Nafion-rGO modified SPE in absence (black curve) and presence (red curve) of $3 \mathrm{mM}$ glucose in $0.1 \mathrm{M} \mathrm{NaOH}$.

The rGO sheets contribute to improve the electrochemical activity of SPEs, and Ni/NiO composite is mainly responsible to provide electrocatalysis activity in alkaline environment.

The CV measurement was further applied to investigate the electrochemical behavior of $\mathrm{Ni} / \mathrm{NiO}-\mathrm{Nafion}-\mathrm{rGO} / \mathrm{SPE}$ in $0.1 \mathrm{M} \mathrm{NaOH}$ absent and present $3 \mathrm{mM}$ glucose (Figure $3 \mathrm{~b}$ ). When glucose is added into the alkaline ambience, the anodic peak current is apparently enhanced accompanied with a positive shift of peak potential from $0.444 \mathrm{~V}$ to $0.558 \mathrm{~V}$, while the cathodic peak abated with a positive shift from $0.387 \mathrm{~V}$ to $0.459 \mathrm{~V}$, which suggests excellent electrocatalytic activity of Ni/NiO-Nafion/rGO in glucose oxidation process. The oxidation of glucose to glucolactone is electrocatalyzed by the $\mathrm{Ni}(\mathrm{III}) / \mathrm{Ni}(\mathrm{II})$ redox couple according to the following electrochemical reaction [23]:

$$
\mathrm{NiOOH}+\text { glucose } \rightarrow \mathrm{Ni}(\mathrm{OH})_{2}+\text { glucolactone }
$$

The enhancement of redox potential is due to adsorption of glucose and the oxidized intermediates on the active sites of $\mathrm{Ni} / \mathrm{NiO}$, which slows down the kinetics of the above reaction. Accordingly, the cathodic peak current reducing is ascribed to the consumption of $\mathrm{Ni}^{3+}(\mathrm{NiOOH})$, which is induced by the oxidation of glucose [14]. 

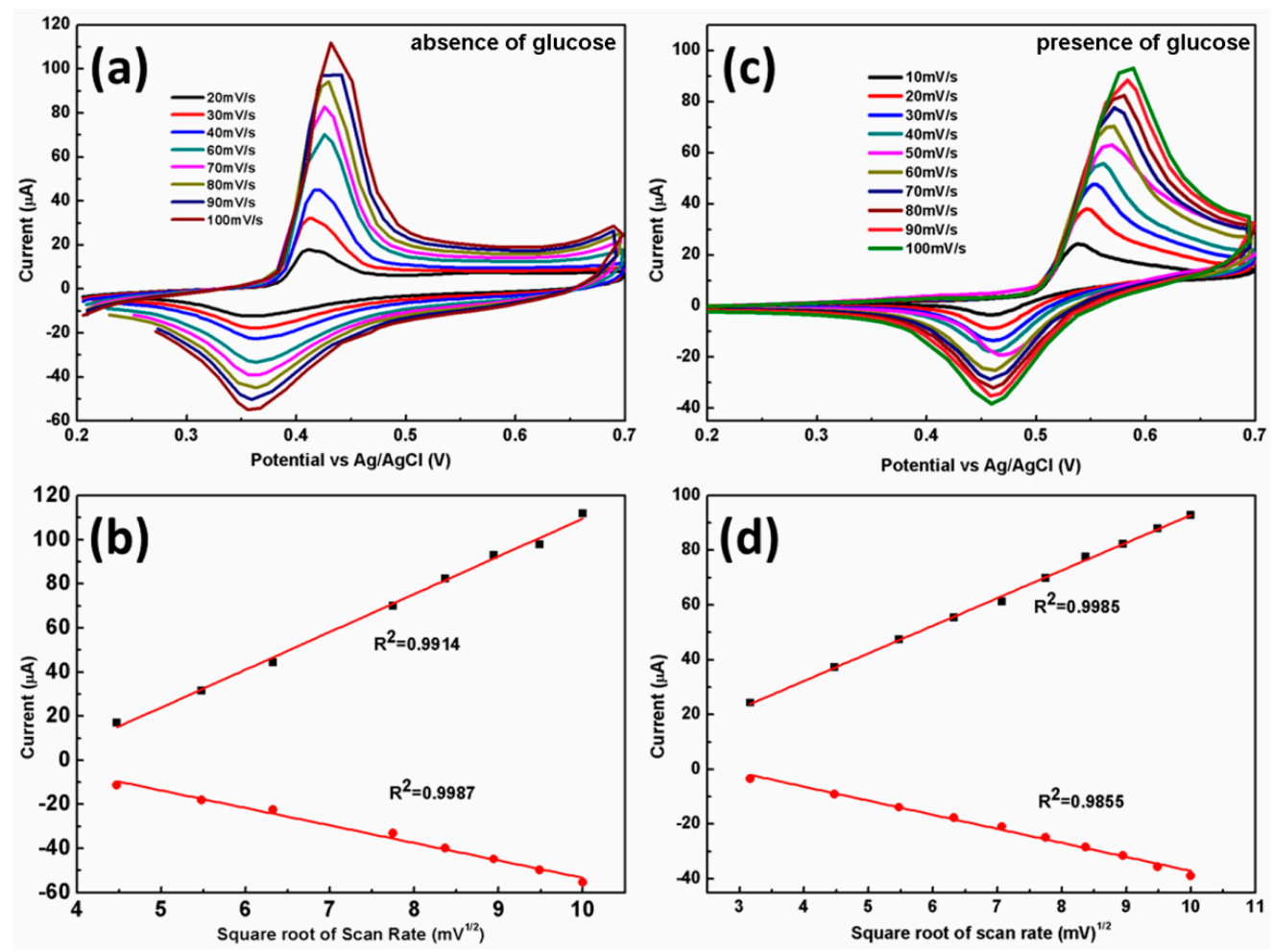

Figure 4. Cyclic voltammograms of Ni/NiO-Nafion-rGO modified SPE in absence (a) and presence (c) of glucose in $0.1 \mathrm{M} \mathrm{NaOH}$ with different scan rate; and plots of peaks current (Ip) vs. square root of scan rate in absence (b) and presence (d) of glucose in $0.1 \mathrm{M} \mathrm{NaOH}$.

Further investigation of electron transfers behaviors of Ni/NiO-Nafion-rGO/SPE is performed using CV technique under various scan rates in absence and presence of glucose in alkaline condition, as shown in Figure 4. With the absence of glucose (Figure 4a), both cathode and anode current peaks linearly increase with the square root of scan rates and excellent correlation coefficients $(0.9914$ and 0.9987) achieves (Figure $4 \mathrm{~b}$ ). It reveals that Reaction (1) is a quasi-reversible electron transfer and diffusion controlled process that depends on $\mathrm{OH}^{-}$diffusion to the electrode surface. With the presence of glucose, the anodic peaks show a positive shift along the scan rate from $0.537 \mathrm{~V}$ to $0.585 \mathrm{~V}$, while the cathodic peaks maintained at $\sim 0.459 \mathrm{~V}$ (Figure $4 \mathrm{c}$ ). The separation of cathode and anode potential increased with scan rate, which implied that the reaction rate decreased with the presence of glucose. Currents of both cathode and anode peak increase linearly with the square root of scan rate, indicating a diffusion controlled process.

\subsection{Performance of Ni/NiO-Nafion-rGO/SPEs Nonenzymatic Glucose Sensors}

The amperometric response of constructed nonenzymatic sensor is evaluated with successive addition of glucose at an applied potential of $0.55 \mathrm{~V}$. As shown in Figure $5 \mathrm{a}$, the current response increases with the addition of various concentration of glucose. A rapid response of the nonenzymatic catalyzed glucose less than $2 \mathrm{~s}$ (reaching $95 \%$ of the steady-state current) is achieved. It can detect glucose linearly from $29.9 \mu \mathrm{M}$ to $6.44 \mathrm{mM}(\mathrm{R}=0.9937)$ with a detection limit of $1.8 \mu \mathrm{M}($ at $\mathrm{S} / \mathrm{N}=3)$, as shown in Figure $5 \mathrm{~b}$. The sensitivity is calculated to be $1997 \mu \mathrm{A} / \mathrm{mM} \cdot \mathrm{cm}^{-2}$. Compared to the performance of other nonenzymatic glucose sensors based on graphene and transition metals (Table 1), the as-fabricated sensor shows an excellent sensitivity and a suitable detection range for human blood monitoring [35]. Besides, the sensitivity of the nonenzymatic sensors is also better than the reported enzymatic sensors [36]. 

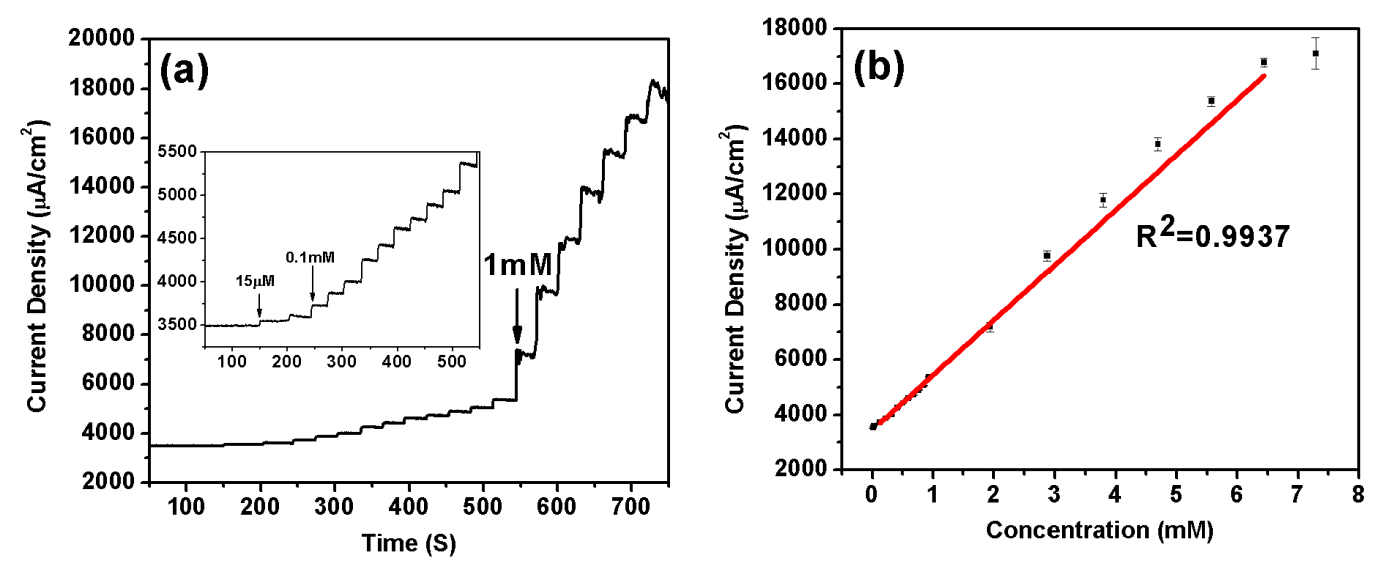

Figure 5. (a) Amperometric response of Ni/NiO-Nafion-rGO nanocomposite modified SPE in a series of concentrations of glucose at an applied potential of $0.55 \mathrm{~V}$ (insert show the magnification of low glucose concentration); (b) Linear calibration curve to the amperometric response.

Table 1. Comparison of the performance of nonenzymatic glucose sensors based on graphene and transition metals. CS: Chitosan; NPs: nanoparticles; GCE: glass carbon electrode; ILE: Ionic-liquid electrode; GR: grapheme.

\begin{tabular}{ccccc}
\hline Sensor & $\begin{array}{c}\text { Detect Limit } \\
(\mu \mathbf{M})\end{array}$ & $\begin{array}{c}\text { Linear Range } \\
(\mathbf{m M})\end{array}$ & $\begin{array}{c}\text { Sensitivity } \\
\left(\mu \mathbf{A} / \mathbf{m} \mathbf{M} \cdot \mathbf{c m}^{-2}\right)\end{array}$ & Reference \\
\hline AuNPs-graphene/ILE & $0.062 / 0.183$ & $/$ & $97.8 / 16.3$ & {$[37]$} \\
GR-Nafion-PdNPs/GCE & 1 & $0.01-5.0$ & $/$ & {$[11]$} \\
CS-rGO-NiNPs/SPE & 4.1 & $0.2-9.0$ & 318.4 & {$[24]$} \\
rGO-Ni(OH) $)_{2} / G C E$ & 0.6 & $0.002-3.1$ & 11.43 & {$[15]$} \\
NiO-GR/GCE & 5 & $0.02-4.5$ & $/$ & {$[38]$} \\
$\mathrm{Ni} / \mathrm{NiO}-\mathrm{rGO}-\mathrm{Nafion} / \mathrm{SPE}$ & 1.8 & $0.03-6.44$ & 1997 & This work \\
\hline
\end{tabular}

The anti-interference experiment of $\mathrm{Ni} / \mathrm{NiO}-\mathrm{Nafion}-\mathrm{rGO} / \mathrm{SPE}$ is investigated by successive addition of $1 \mathrm{mM}$ glucose, $0.1 \mathrm{mM}$ LA, $0.1 \mathrm{mM}$ UA, $0.1 \mathrm{mM}$ BSA, $0.1 \mathrm{mM}$ AA, and $2 \mathrm{mM}$ glucose at an applied potential of $0.55 \mathrm{~V}$, as shown in Figure 6a. The addition of above inferences apparently did not induce current response, while current response to $3 \mathrm{mM}$ glucose is $\sim 9600 \mu \mathrm{A} / \mathrm{cm}^{2}$.

The reproducibility of $\mathrm{Ni} / \mathrm{NiO}-\mathrm{Nafion}-\mathrm{rGO}-\mathrm{SPE}$ is investigated from the current response to $3 \mathrm{mM}$ glucose at 10 individual devices, as shown in Figure $6 \mathrm{~b}$. A good reproducibility with relative standard deviation (RSD) of $1.46 \%$ is achieved. Furthermore, the average current response to $3 \mathrm{mM}$ glucose is calculated to be $9624 \mu \mathrm{A} / \mathrm{cm}^{2}$.
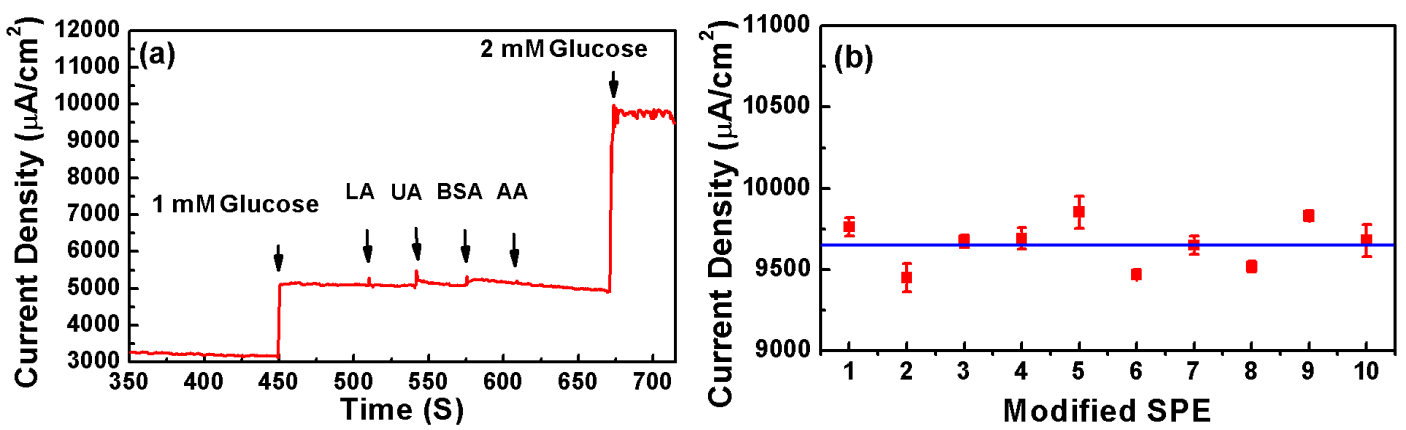

Figure 6. (a) Selectivity measurement of amperometric responses to successive addition of $1 \mathrm{mM}$ glucose, $0.1 \mathrm{mM}$ LA, $0.1 \mathrm{mM}$ UA, $0.1 \mathrm{mM}$ BSA, $0.1 \mathrm{mM}$ AA, and $2 \mathrm{mM}$ glucose; (b) Reproducibility measurement of 10 amperometric response towards $3 \mathrm{mM}$ glucose. 


\section{Conclusions}

In situ synthesized Ni/NiO-rGO nanocomposite modified SPEs were applied to the sensitively detection of glucose free of enzyme. This $\mathrm{Ni} / \mathrm{NiO}-\mathrm{Nafion}-\mathrm{rGO} / \mathrm{SPE}$ nonenzymatic glucose sensor shows a high electrochemical activity for electrocatalytic oxidation of glucose in alkaline medium. The constructed nonenzymatic biosensor presented a wide linear range from $29.9 \mu \mathrm{M}$ to $6.44 \mathrm{mM}$ $(\mathrm{R}=0.9937)$, a low detection limit of $1.8 \mu \mathrm{M}(\mathrm{S} / \mathrm{N}=3)$, a fast response of less than $2 \mathrm{~s}$, and a sensitivity as high as $1997 \mu \mathrm{A} / \mathrm{mM} \cdot \mathrm{cm}^{-2}$. Besides, good reproducibility and high selectivity were also demonstrated. The proposed sensor can be facilely fabricated, which allows for economical and miniaturized construction of lab-on-chip devices. It also reveals a great potential for graphene based materials to be utilized in surface and interface science.

Acknowledgments: This work was supported by the National Major Research Program of China (2013CB932602), the Major Project of International Cooperation and Exchanges (2012DFA50990), NSFC (51232001, 51172022, 51372020, 51602020, and 51002008), the Program of Introducing Talents of Discipline to Universities, the Fundamental Research Funds for Central Universities, Program for New Century Excellent Talents in University, the China Postdoctoral Science Foundation (2016T90033 and 2015M580981), and the Program for Changjiang Scholars and Innovative Research Teams in Universities.

Author Contributions: Zheng Zhang and Xiaohui Zhang synthesized the Ni/NiO-Graphene Nanocomposite. Zheng Zhang characterized the structure and properties of the nanocomposite. Xiaohui Zhang performed the device fabrication, data collection and analysis. Qingliang Liao and Shuo Liu assisted the nanocomposite fabrication and characterizations. Zhuo Kang assisted in the device performance measurements. Xiaohui Zhang, Zheng Zhang and Yue Zhang initiated and supervised the project. All authors discussed the results, and prepared and commented on the manuscript. Xiaohui Zhang and Zheng Zhang contributed to this work equally.

Conflicts of Interest: The authors declare no conflict of interest.

\section{References}

1. Wild, S.; Roglic, G.; Green, A.; Sicree, R.; King, H. Global prevalence of diabetes: Estimates for the year 2000 and projections for 2030. Diabetes Care 2004, 27, 1047-1053. [CrossRef] [PubMed]

2. Clark, L.C., Jr.; Lyons, C. Electrode systems for continuous monitoring in cardiovascular surgery. Ann. N. Y. Acad. Sci. 1962, 102, 29-45. [CrossRef] [PubMed]

3. Scognamiglio, V. Nanotechnology in glucose monitoring: Advances and challenges in the last 10 years. Biosens. Bioelectron. 2013, 47, 12-25. [CrossRef] [PubMed]

4. Lei, Y.; Yan, X.; Zhao, J.; Liu, X.; Song, Y.; Luo, N.; Zhang, Y. Improved glucose electrochemical biosensor by appropriate immobilization of nano-ZnO. Colloids Surf. B 2011, 82, 168-72. [CrossRef] [PubMed]

5. Lei, Y.; Yan, X.Q.; Luo, N.; Song, Y.; Zhang, Y. ZnO nanotetrapod network as the adsorption layer for the improvement of glucose detection via multiterminal electron-exchange. Colloids Surf. A 2010, 361, 169-173. [CrossRef]

6. Zhang, W.D.; Chen, J.; Jiang, L.C.; Yu, Y.X.; Zhang, J.Q. A highly sensitive nonenzymatic glucose sensor based on NiO-modified multi-walled carbon nanotubes. Microchim. Acta 2010, 168, 259-265. [CrossRef]

7. Xiao, F.; Zhao, F.Q.; Mei, D.P.; Mo, Z.R.; Zeng, B.Z. Nonenzymatic glucose sensor based on ultrasonic-electrode position of bimetallic $\mathrm{PtM}(\mathrm{M}=\mathrm{Ru}, \mathrm{Pd}$ and $\mathrm{Au})$ nanoparticles on carbon nanotubes-ionic liquid composite film. Biosens. Bioelectron. 2009, 24, 3481-3486. [CrossRef] [PubMed]

8. Wang, J.X.; Sun, X.W.; Cai, X.P.; Lei, Y.; Song, L.; Xie, S.S. Nonenzymatic glucose sensor using freestanding single-wall carbon nanotube films. Electrochem. Solid State Lett. 2007, 10, J58-J60. [CrossRef]

9. Gao, H.C.; Wang, Y.X.; Xiao, F.; Ching, C.B.; Duan, H.W. Growth of Copper Nanocubes on Graphene Paper as Free-Standing Electrodes for Direct Hydrazine Fuel Cells. J. Phys. Chem. C 2012, 116, 7719-7725. [CrossRef]

10. Xu, F.G.; Sun, Y.J.; Zhang, Y.; Shi, Y.; Wen, Z.W.; Li, Z. Graphene-Pt nanocomposite for nonenzymatic detection of hydrogen peroxide with enhanced sensitivity. Electrochem. Commun. 2011, 13, 1131-1134. [CrossRef]

11. Lu, L.M.; Li, H.B.; Qu, F.; Zhang, X.B.; Shen, G.L.; Yu, R.Q. In situ synthesis of palladium nanoparticle-graphene nanohybrids and their application in nonenzymatic glucose biosensors. Biosens. Bioelectron. 2011, 26, 3500-3504. [CrossRef] [PubMed] 
12. Liu, Y.; Teng, H.; Hou, H.Q.; You, T.Y. Nonenzymatic glucose sensor based on renewable electrospun Ni nanoparticle-loaded carbon nanofiber paste electrode. Biosens. Bioelectron. 2009, 24, 3329-3334. [CrossRef] [PubMed]

13. Lu, L.M.; Zhang, L.; Qu, F.L.; Lu, H.X.; Zhang, X.B.; Wu, Z.S.; Huan, S.Y.; Wang, Q.A.; Shen, G.L.; Yu, R.Q. A nano-Ni based ultrasensitive nonenzymatic electrochemical sensor for glucose: enhancing sensitivity through a nanowire array strategy. Biosens. Bioelectron. 2009, 25, 218-223. [CrossRef] [PubMed]

14. Ci, S.; Huang, T.; Wen, Z.; Cui, S.; Mao, S.; Steeber, D.A.; Chen, J. Nickel oxide hollow microsphere for non-enzyme glucose detection. Biosens. Bioelectron. 2014, 54, 251-257. [CrossRef] [PubMed]

15. Zhang, Y.; Xu, F.G.; Sun, Y.J.; Shi, Y.; Wen, Z.W.; Li, Z. Assembly of $\mathrm{Ni}(\mathrm{OH})_{2}$ nanoplates on reduced graphene oxide: A two dimensional nanocomposite for enzyme-free glucose sensing. J. Mater. Chem. 2011, 21, 16949-16954. [CrossRef]

16. Wang, G.F.; He, X.P.; Wang, L.L.; Gu, A.X.; Huang, Y.; Fang, B.; Geng, B.Y.; Zhang, X.J. Non-enzymatic electrochemical sensing of glucose. Microchim. Acta 2013, 180, 161-186. [CrossRef]

17. Wang, Z.; Hu, Y.; Yang, W.; Zhou, M.; Hu, X. Facile one-step microwave-assisted route towards Ni nanospheres/reduced graphene oxide hybrids for non-enzymatic glucose sensing. Sensors 2012, 12, 4860-4869. [CrossRef] [PubMed]

18. Novoselov, K.S.; Geim, A.K.; Morozov, S.V.; Jiang, D.; Zhang, Y.; Dubonos, S.V.; Grigorieva, I.V.; Firsov, A.A. Electric field effect in atomically thin carbon films. Science 2004, 306, 666-669. [CrossRef] [PubMed]

19. Geim, A.K. Graphene: status and prospects. Science 2009, 324, 1530-1534. [CrossRef] [PubMed]

20. Zhang, X.; Zhang, Y.; Liao, Q.; Song, Y.; Ma, S. Reduced graphene oxide-functionalized high electron mobility transistors for novel recognition pattern label-free DNA sensors. Small 2013, 9, 4045-4050. [CrossRef] [PubMed]

21. Zhang, X.; Liao, Q.; Chu, M.; Liu, S.; Zhang, Y. Structure effect on graphene-modified enzyme electrode glucose sensors. Biosens. Bioelectron. 2014, 52, 281-287. [CrossRef] [PubMed]

22. Zhang, W.; Du, D.; Gunaratne, D.; Colby, R.; Lin, Y.; Laskin, J. Polyoxometalate-Graphene Nanocomposite Modified Electrode for Electrocatalytic Detection of Ascorbic Acid. Electroanalysis 2014, 26, 178-183. [CrossRef]

23. Zhang, Y.; Xiao, X.P.; Sun, Y.J.; Shi, Y.; Dai, H.C.; Ni, P.J.; Hu, J.T.; Li, Z.; Song, Y.H.; Wang, L. Electrochemical Deposition of Nickel Nanoparticles on Reduced Graphene Oxide Film for Nonenzymatic Glucose Sensing. Electroanalysis 2013, 25, 959-966. [CrossRef]

24. Yang, J.; Yu, J.H.; Rudi Strickler, J.; Chang, W.J.; Gunasekaran, S. Nickel nanoparticle-chitosan-reduced graphene oxide-modified screen-printed electrodes for enzyme-free glucose sensing in portable microfluidic devices. Biosens. Bioelectron. 2013, 47, 530-538. [CrossRef] [PubMed]

25. Zhang, X.; Liao, Q.; Liu, S.; Xu, W.; Liu, Y.; Zhang, Y. CuNiO nanoparticles assembled on graphene as an effective platform for enzyme-free glucose sensing. Anal. Chim. Acta 2015, 858, 49-54. [CrossRef] [PubMed]

26. Wang, J.; Pedrero, M.; Sakslund, H.; Hammerich, O.; Pingarron, J. Electrochemical activation of screen-printed carbon strips. Analyst 1996, 121, 345-350. [CrossRef]

27. Ferrari, A.C.; Meyer, J.C.; Scardaci, V.; Casiraghi, C.; Lazzeri, M.; Mauri, F.; Piscanec, S.; Jiang, D.; Novoselov, K.S.; Roth, S.; et al. Raman spectrum of graphene and graphene layers. Phys. Rev. Lett. 2006, 97, 187401. [CrossRef] [PubMed]

28. Zhan, Z.; Zheng, L.; Pan, Y.; Sun, G.; Li, L. Self-powered, visible-light photodetector based on thermally reduced graphene oxide-ZnO (rGO-ZnO) hybrid nanostructure. J. Mater. Chem. 2012, 22, 2589-2595. [CrossRef]

29. Reina, A.; Jia, X.; Ho, J.; Nezich, D.; Son, H.; Bulovic, V.; Dresselhaus, M.S.; Kong, J. Large area, few-layer graphene films on arbitrary substrates by chemical vapor deposition. Nano lett. 2009, 9, 30-35. [CrossRef] [PubMed]

30. Goncalves, G.; Marques, P.A.A.P.; Granadeiro, C.M.; Nogueira, H.I.S.; Singh, M.K.; Gracio, J. Surface Modification of Graphene Nanosheets with Gold Nanoparticles: The Role of Oxygen Moieties at Graphene Surface on Gold Nucleation and Growth. Chem. Mater. 2009, 21, 4796-4802. [CrossRef]

31. Kim, J.H.; Kwon, S.Y.; Bhattacharjya, D.; Chai, G.S.; Yu, J.S. High-performance quaternary PtRuIrNi electrocatalysts with hierarchical nanostructured carbon support. J. Catal. 2013, 306, 133-145. [CrossRef]

32. Grim, S.O.; Matienzo, L.J.; Swartz, W.E. X-ray photoelectron spectroscopy of some nickel dithiolate complexes. J. Am. Chem. Soc. 1972, 94, 5116-5117. [CrossRef] 
33. Li-Shing, H.; Williams, R.S. Electronic-structure study of the $\mathrm{Ni}_{3} \mathrm{Ga}$ and the NiIn intermetallic compounds using X-ray photoemission spectroscopy. J. Phys. Chem. Solids 1994, 55, 305-312. [CrossRef]

34. Lu, W.; Qin, X.; Asiri, A.M.; Al-Youbi, A.O.; Sun, X. Ni foam: a novel three-dimensional porous sensing platform for sensitive and selective nonenzymatic glucose detection. Analyst 2013, 138, 417-420. [CrossRef] [PubMed]

35. Tian, K.; Prestgard, M.; Tiwari, A. A review of recent advances in nonenzymatic glucose sensors. Mater. Sci. Eng. C 2014, 41, 100-118. [CrossRef] [PubMed]

36. Tian, K.; Alex, S.; Siegel, G.; Tiwari, A. Enzymatic glucose sensor based on Au nanoparticle and plant-like ZnO film modified electrode. Mater. Sci. Eng. C 2015, 46, 548-552. [CrossRef] [PubMed]

37. Wu, J.W.; Wang, C.H.; Wang, Y.C.; Chang, J.K. Ionic-liquid-enhanced glucose sensing ability of non-enzymatic $\mathrm{Au}$ /graphene electrodes fabricated using supercritical $\mathrm{CO}_{2}$ fluid. Biosens. Bioelectron. 2013, 46, 30-36. [CrossRef] [PubMed]

38. Zhu, X.H.; Jiao, Q.F.; Zhang, C.Y.; Zuo, X.X.; Xiao, X.; Liang, Y.; Nan, J.M. Amperometric nonenzymatic determination of glucose based on a glassy carbon electrode modified with nickel(II) oxides and graphene. Microchim. Acta 2013, 180, 477-483. [CrossRef]

(C) 2016 by the authors; licensee MDPI, Basel, Switzerland. This article is an open access article distributed under the terms and conditions of the Creative Commons Attribution (CC-BY) license (http://creativecommons.org/licenses/by/4.0/). 